\title{
A CIRCULATOR TO ELIMINATE MECHANICAL DEAD SPACE IN CIRCLE ABSORPTION SYSTEMS
}

\author{
DAN G. REVELL, M.D. ${ }^{1}$
}

THE POTENCY, versatility, and usefulness of cyclopropane are acknowledged by most physicians, but the fact that for economy reasons cyclopropane is ordinarily used in a closed system has restricted its application in paediatric anaesthesia because of the important attendant disadvantages of dead space and resistance.

The desire to avord the unpleasantness and drawbacks of frank ether and to make cyclopropane avalable to tiny patients led to the development of the apparatus described below This original apparatus for the elımination of the dead space is added to ordinary equipment used in closed and semi-closed anaesthisia. The clinical application has been very rewarding and has extended over a period of ten years.

\section{DEsCRIPTION}

The apparatus devised to elıminate the mechanical dead space may be referred to as a circulator since its function is to keep the gases in the under-mask space moving so that each breath as it is exhaled is carried away towards the absorber In other words, the gases in the crrcle are kept in motion and the patient breathes out to and in from a passing breeze of fresh gases. This prevents the reinhalation of that part of the exhaled gases coming from the depths of the lungs which contains the highest concentration of carbon dioxide and the least oxygen.

The component parts of the device are a divided chimney-piece and a pump (Fig. 1). It is necessary to have a divided chimney-piece to produce a flow pattern that will change the gases in the under-mask space This change is accomplished by a median septum, so that inhaled gases pass down one side and exhaled gases pass up the other. This chimney-piece is of male-desı̨̧n and fits into the top of masks of the Heidbrink and M.I.E. pattern so that tae septum can be carried right into the under-mask space. In operation the circulating pump draws gases free of carbon dioxide from the breathing bag and delivers them into the inhalation side of the crrcle at a point where they will force the gases along the corrugated connecting tube towards the mask. The under-mask gases are thus continuously kept moving towards the exhalation valve of the machine' and thence through the absorber back to the bag.

The circulating pump is constructed from two identical suction Trico automobile windshie d-wiper motors of a type in very common use. These motors are joined firmly together by their ends in such a manner that their external moving parts may also be coupled together. The two are intercoupled by a metal sling by which they are hung on and grounded $\tau_{7}$ the gas machme $\left(F_{1} g_{5} 2\right)$ One of these units powered by suction is operated as the motor and when in motion 1St Joseph's Hospital, Victona, B C

Can Anaes. Soc J., vol. 6, no 2, April, 1959 


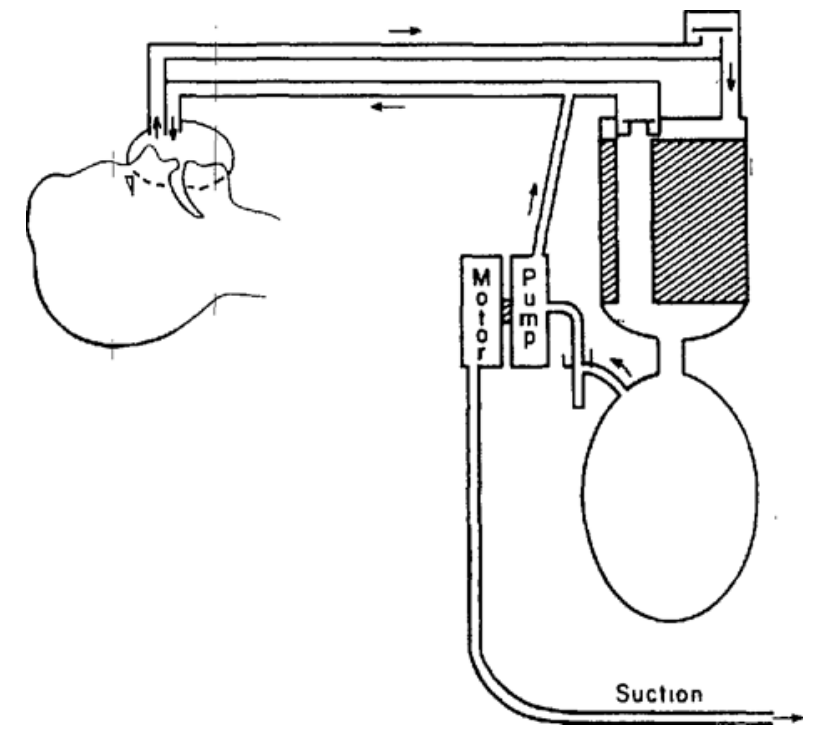

Figure 1. Circulator attached to circle gas machune The motor, powered by suction, drives the pump which draws from the rebreath-bag and delivers gases into the inhalation side of the circle A moisture-condenser-trap is interposed between the bag and the pump The curculator causes a contunuous change of the gases under the mask, displacing the exhaled gases towards' the absorber thus preventing reinhalation of gases containing carbon dioxide The divided chimney-prece is essentral to pattern the gas flow under the mask

drves the other, which then becomes a pump. It is essential that the reversing mechanism of the motor be adjusted to allow the pump to execute a complete cycle in each drrection. That 1 , the reversing mechanısm of the pump must trip just before that of the motor. Making this adjustment requires an understanding of the reversing mechanism but is easily made with a file The cover plate over the reversing parts of the pump must be fitted with a metal nipple, which becomes the intake port. All gaskets must be gas-tight on the pump. The control lever on the pump is wred in the open position while that of the motor is used to turn the motor on and off. The rate of motor operation depends on the strength of the suction available and is adjusted by a screw clamp on the rubber tube leading to the motor. The capacity of the Trico motors used is about $50 \mathrm{cc}$; so one can calculate the volume of the gases pumped for a given rate of oscillation. It has been found that a rate of fifty cycles per minute (one hundred clicks of the reversing mechanism) will change the under-mask gases at a rate of $5 \mathrm{~L}$. per minute. This has appeared clinically to be a satisfactory rate.

Owing to the high humidity of the gases pumped a condenser and water-trap is interposed between the rebreathing bag and the pump. This is cooled by the evaporation of alcohol or water poured into a small reservoir around the base of 
the condenser The purnp intake mpple is connected to the breathing bag by means of a hollow bolt held in place by two plastre washers and a nut The output of the pump is carned by a short rubber tube leading into the inhalation side of the curcle just above and on the patient's side of the mhalation valve

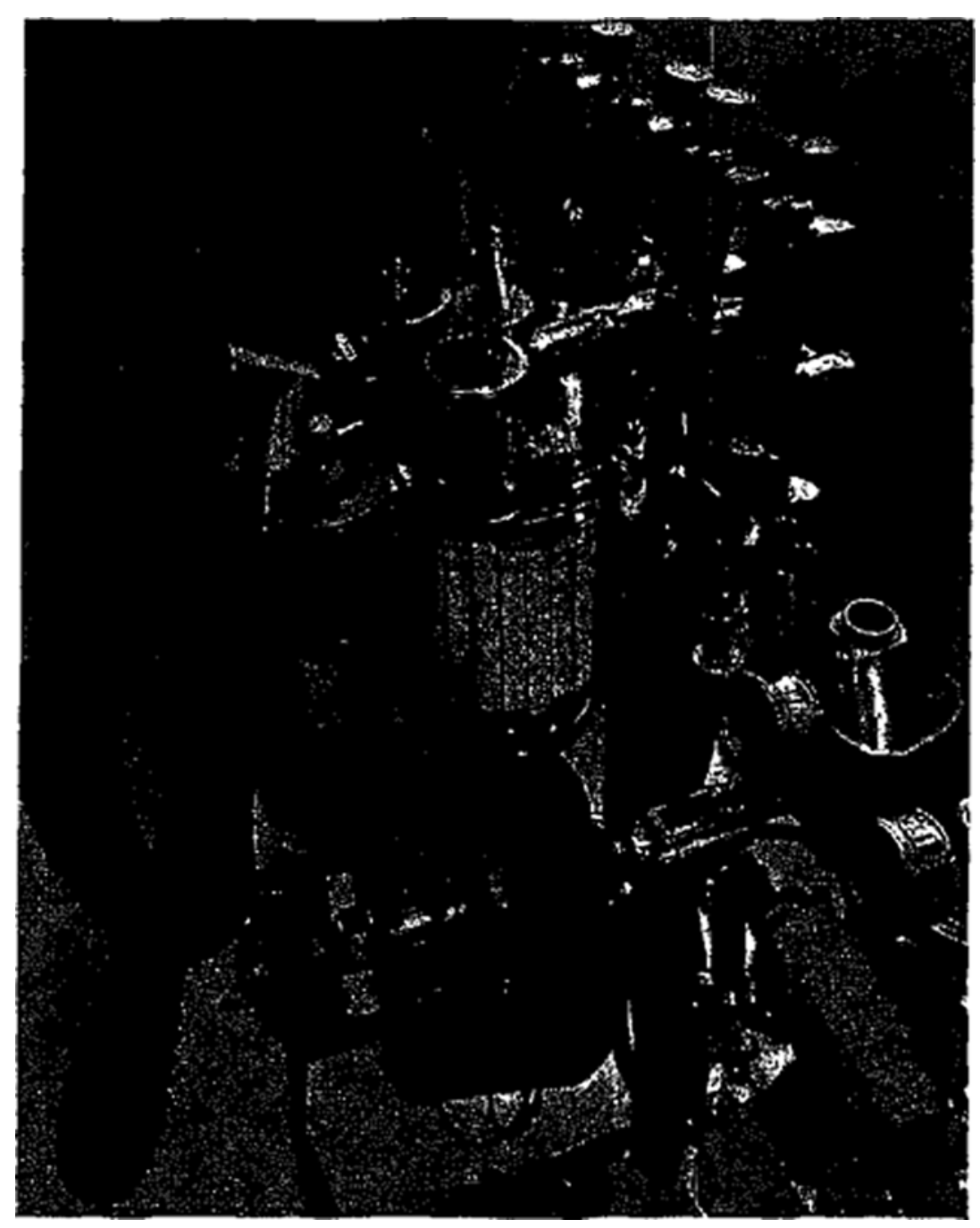

Ficture 2 An early model of crculator attached to a Heudbrinh machine The motor-pump is suspended from the ether-jar and the rate control clip has been omitted Note the divided chunney-piect and the molsture condenser-trap

Since the circulator pump has a vane-type piston oscillabng between two cylunders, one side is discharging its gases at the same time and rate as the other is filling Thus the pump removes and replaces gases from and to the circle system of the anaesthetic machine without disturbing the volume or causing the breathing bag to pulsate Therefore, the operation of the corculator does not alter the behaviour of the bag as an index of anaesthetic depth, nor is the effectrveness of the curculator interfered with by the anaesthetist assisting or augmenting respuration by intermittent compression of the bag 


\section{Discussron}

The anatomical dead space comprises the tracheobronchial tree and the upper respiratory tract. The mechanical or the anaesthetic dead space is extracorporeal and is mechanically imposed on the patient by the use of any anaesthetic equipment such as the open drop mask or the mask and connecting chimney-piece necessary to closed or semi-closed techniques. The smaller the tidal volume, the more deleterious to the patient is the imposed dead space. In small patients, and adults whose tidal volume is for any reason reduced, addition of mechanical dead space may lead to hypoxia and accumulation of carbon dioxide durnng anaesthesia.

The circulator allows the use of a variety of masks and reduces the need for intubation as a means of reducing dead space in many paediatric cases. Resistance to mhalation ordinarily created by the tubing and valves of the circle system is absent and exhalation is very little impeded. The slight positive undermask pressure is an and to inhalation, especially for very small patients The circulator must not be confused with other recently evolved pumps or ventilators which are designed to assist with the respiratory movements of the patient, or carry out controlled respiration The circulator is used merely to reduce the imposed dead space.

A special application of the curculator is its use to pertorm closed endotracheal sufflation which reduces even the anatomical dead space ( $\left.F_{1 g} 3\right)$. This has been

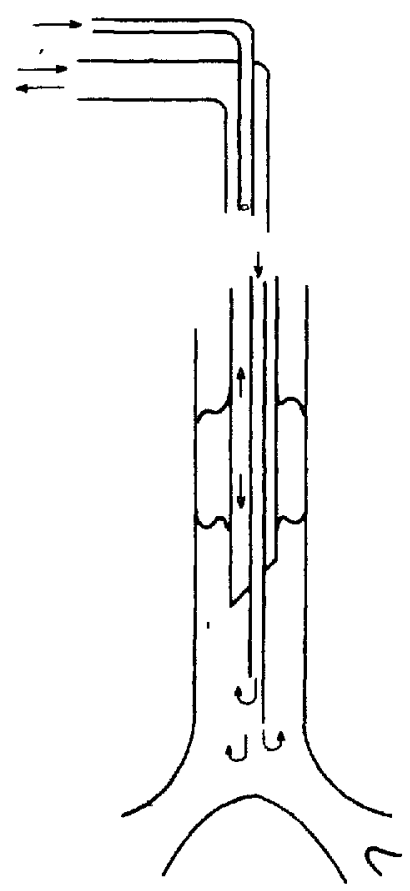

Figure 3 Set-up for closed endotracheal sufflation The tube carrying gases from the pump is led into the endotracheal catheter at the angle adapter and extends a short distance beyond the end of the catheter. By reversing the direction of flow and connections into the circle, and interposing a liquid-catching trap, a technique of continuous closed endotracheal suction may be used. The air line to the cuff has been omitted. 
done in patients undergoing open chest surgery, where it is felt that the most can be made of diffusion exchange of fresh gases introduced near the carina This technique is not used alone, but in addition to the usual manual ventilation. Also by reversing the set-up, conthuous closed endotracheal suction can be performed. The blood and pus are trapped in a small bottle and the gases are returned to the closed circle on the exhalation side. To carry out either of these techniques a thin-walled polythene tube, such as is used in disposable intravenous sets, is passed down inside the endotracheal tube to a point near the carina. This requires the use of an endotracheal adapter drilled at a point where the projected axis of the endotracheal tube meets the metal. The polythene tube should fit snugly enough to be gas-tight for ordinary pressures. The presence of the smaller tube within the larger does reduce the calibre somewhat, but plenty of room is left for adequate exchange since augmented or controlled respiration is used in these cases.

The advantages of the circulator are easily recognized in paediatric anaesthesia. It is just as logical to suggest its use also in all adult closed or semi-closed techniques for the same purpose of minimizing the ill effects of increased dead space.

In ether vaporizers which depend upon the flow of respired gases in the circle apparatus vaporization is accelerated by the additional flow provided by the circulator. This facilitates àchievement of the desired level of surgical anaesthesia, but adds the danger of easily produced overdosage.

On those occasions when nitrogen is desired as a diluent to the anaesthetic mixture it can be readily added from the ambient atmosphere by momentarily opening the pump intake to the room air.

\section{SUMMARY}

A descriptıon is given of an original apparatus for the removal of the undermask dead space in paediatric anaesthesia. Its application to adult anaesthesia is also suggested. The apparatus may be used in conjunction with any circle closed or semi-closed absorption technique. The principle of operation is the forcing of carbon dioxide free gases through the under-mask space in order to displace the exhaled atmosphere before the next inhalation takes place. The technique has been used in all the writer's paediatric cases since 1947 and in those of his associates in the last five years.

\section{ADDENDUM}

The author is aware that a double chimney-piece and a hand-operated bulb pump have been described in the literature in recent years. The author's divided chimney-piece which has been in use for more than ten years was sent to the Heidbrink Division of the Ohio Chemical Company in Madison, Wisconsin, in 1947, and its use explained as a means of reducing the dead space in conventional chimney-วieces. A chimney-piece of this exact design is now available from Heidbrin $x$. The use of the circulator and its development were presented in a 
formal paper to the British Columbia Division of the Canadian Anaesthetists' Society in Victoria in 1949 and again before the Pacific Northwest Society of Anesthetists at Portland, Oregon, in September, 1950. Though not on the programme, the circulator was shown in the commercial exhibits at the Western Regional Conference in San Francisco in March 1949.

\section{RÉSUMÉ}

Nous avons décrit un appareil original qui peut être utilisé en anest aésie lorsque l'on se sert d'un circuit fermé ou semi-fermé avec absorption. L'usą̧, de cet appareil a pour effet d'éliminer l'espace mort mécanique inévitable en act.vant continuellement la circulation des gaz inspirés. L'usage d'une pompe à succion et d'un tube connecteur à deux branches maintiennent en circulation les gaz dans le circuit, les diluant et enlevant du masque les gaz exhalés avant l'inhalation suivante. Ceci diminue l'irnportance du petit volume d'air courant des enfants et permet l'usage de l'outillage pour adultes avec toute sécurité dans les cas de pédıâtrie. Cet appareil est sans fantaisie et ne comporte pas les risques d'explosion que cachent les appareils électriques Sa grande valeur est de permettre l'usage d'une technique fermée et semi-fermée sans espace mort additionnel. L'appareil, avec un ajustement spécial, rend possible l'insufflation endotrachéale continue ou la succion dans un circuit fermé, système qui peut être pratique dans certains cas de chirurgie pulmonaire. Il ne s'agit pas d'un vẹntilateur mécanique mais d'un circulateur qui réduit la supposée accumulation de gaz carbonique en changeant continuellement les gaz dans le masque. Nous employons cette technique depuis dix ans. Parmi les nombreux cas où cet a jpareil a servi, nous comptons des nouveaux-nés pesant aussi peu que quatre livres. 